\title{
The scientific building blocks for business coaching: A literature review
}

\author{
Authors: \\ Flip Schutte ${ }^{1}$ \\ Renier Steyn ${ }^{1}$ \\ Affiliations: \\ ${ }^{1}$ Graduate School of Business \\ Leadership, University of \\ South Africa, South Africa \\ Correspondence to: \\ Renier Steyn \\ Email: \\ steynr@unisa.ac.za \\ Postal address: \\ PO Box 392, University \\ of South Africa 0003, \\ South Africa \\ Dates: \\ Received: 06 Aug. 2014 \\ Accepted: 23 Jan. 2015 \\ Published: 26 Mar. 2015 \\ How to cite this article: \\ Schutte, F., \& Steyn, R. \\ (2015). The scientific building \\ blocks for business coaching: \\ A literature review. SA \\ Journal of Human Resource \\ Management/SA Tydskrif vir \\ Menslikehulpbronbestuur, \\ 13(1) Art. \#657, 11 pages. \\ http://dx.doi.org/10.4102/ \\ sajhrm.v13i1.657

\section{Copyright:} \\ (C) 2015. The Authors. \\ Licensee: AOSIS \\ OpenJournals. This work is \\ licensed under the Creative \\ Commons Attribution \\ License.
}

Read online:
Orientation: Business coaching is a relatively new approach to leadership development. It is also slowly growing as an academic discipline with only a small number of active researchers and a dearth of published literature reviews.

Research purpose: This article is an investigation into the current level of development of the body of knowledge related to business coaching by means of a systematic literature review.

Motivation of the study: Previous literature reviews summarised the available published articles. In order to contribute to establishing business coaching as an independent academic discipline, the building blocks for science in the phenomenon under investigation have to be scientifically not only summarised, but also synthesised and explored to ground this new discipline as an academic field of research.

Research design, approach and method: A methodological framework has been developed to analyse the information. The data were synthesised according to the following building blocks for science: concepts, definitions, typologies, models, theories and paradigms.

Main findings: A total of 84 articles were accessed by the specified search strategy and 36 were analysed according to inclusive and exclusive criteria. Although coaching has not been sufficiently developed as an academic discipline, it is possible to develop a comprehensive definition of coaching, as well as to identify the main models and theories that apply to this field.

Practical/managerial implications: This literature review has synthesised and summarised the available data in such a way that it will contribute to the conceptualisation and foundation of business coaching as an academic discipline.

Contribution: The building blocks for business coaching as a relatively new and emerging science within the field of business leadership have been defined. This will contribute to the articulation of concepts within this discipline by future researchers and practitioners.

\section{Introduction}

\section{Key focus of the study}

For many years almost every article published on business coaching started with the same sentence, namely that business coaching is a newcomer to the world of business and an emerging industry that still needs some time to develop (Clegg Rhodes, Kornberger \& Stilin, 2005; King \& Eaton, 1999). Although it is a growing industry (Shelley, 2008), the academic research on the topic is still in its infancy and there is a need for empirical work in this field (Beets \& Goodman, 2012). Coaching appears not yet to be an academic discipline standing on its own (April \& April, 2007). Evidence of this is the fact that the conceptual and operational identity of coaching is also still unclear (Cilliers, 2005).

It is important to note that there is not an absence of knowledge on coaching, only that this knowledge is in its nature more practical because it describes the way in which coaching practitioners operate in their specific industries. This makes the knowledge more context specific. Therefore literature on coaching is mainly found in popular journals and magazines (Cilliers, 2005), including popular books on this matter (see Upton, 2006 and B. Anderson, 2007, as examples).

Coaching is also addressed as part of management and leadership training together with themes such as mentoring in some Master of Business Administration courses (April \& April, 2007). Empirical research on coaching, however, is according to Passmore and Gibbes (2007) mostly done by students and researchers at postgraduate level. The results of this research have 
remained largely unpublished (Passmore \& Gibbes, 2007). There has more recently been a shift in the themes of articles, away from describing practices, to asking questions about the effectiveness of coaching (Bowles, Cunningham, De La Rosa \& Picano, 2007).

The present study aims, firstly, to explore the literature regarding the way in which literature reviews have to be done. The results of this investigation will then, in the second instance, be used as a lens to investigate the published articles in the field of business coaching. This will result in the compilation of a comprehensive updated literature review that can form a basis for future academic research on the subject of business coaching.

\section{Background to the study}

In order to assess the level of knowledge on coaching, it is important to stipulate to what extent it contains the elements included in a comprehensive body of scientific knowledge. Mouton (1996) provides a simple scheme of elements of a scientific body of knowledge. At the most basic level scientific knowledge is made up of concepts. Concepts act as the carriers of meaning. When associated concepts are combined and sentences formed, one arrives at statements or propositions. When related statements are combined, more complex conceptual frameworks such as typologies, models, theories and eventually broad theoretical paradigms and research traditions are created (Mouton, 1996).

Information should only be added to the body of knowledge once it is accepted by the scientific community (Mouton, 1996). The community will only do so once the information (theory or hypothesis) has been submitted for evaluation by relevant experts. Only when they have scrutinised and accepted the information as a plausible claim will they endorse and disseminate it, namely publish it (Babbie \& Mouton, 2012). Academic knowledge is thus mostly disseminated through peer-reviewed academic journals.

\section{Research purpose}

Some efforts have been made to explore the body of knowledge captured in the literature and several literature reviews in the domain of coaching have already been published. One of the earliest literature reviews on business coaching was done by Kilburg (1996). He concludes that there is a dearth of empirical research on the actual work of practitioners in the field and that most of the available literature is devoted to managers exerting themselves to add coaching to their roles to empower subordinates. He found only two researched studies that could form a scientific basis for what is called business coaching (Kilburg, 1996). Kampa-Kokesch and Anderson (2001) published a comprehensive literature review on executive coaching. These authors conclude that the extant literature provides some basis for understanding definitions, purposes, processes, methodologies, clients and service providers, but that surprisingly little empirical research has been done on the efficacy of executive coaching.
In 2005, Joo reviewed a total of 78 articles on coaching, of which only 11 were research articles published in academic journals. The rest were published in non-academic magazines. The most important conclusion Joo (2005) draws from the empirical articles is that business coaching has become increasingly popular despite limited empirical evidence about its impact. The problem is thus not the practice per se, but the lack of research and theory to advance the field. Joo, in his reporting on business coaching, categorises the articles according to research methodology, definitions and the purpose of the articles.

The last comprehensive literature review on business coaching was done by Passmore and Gibbes (2007). They built upon the work of Kampa-Kokesch and Anderson (2001). They focused mainly on executive coaching as a discipline. Their primary finding was that there is a general shortage of empirical research on business coaching. They concluded that more research to understand the impact of coaching on performance needs to be done. They also recommended that research that describes the nature of the coaching intervention must get more attention.

The present literature review on business coaching is thus not conducted in a vacuum, but aims to close the gap since the last comprehensive literature review was done by Passmore and Gibbes (2007). The aim of this article is to report on the present level of knowledge on coaching by means of the scheme provided by Mouton (1996), taking into account the existing literature reviews and other research articles published since the work of Passmore and Gibbes.

\section{Trends from the research literature}

The first part of this article is a literature review on how literature reviews are done. The result of this investigation will then be used in the second part of the article to conduct a literature review on the available literature on business coaching.

Systematic literature reviews have become widely accepted during the past 20 years (Kable, Pich \& Maslin-Prothero 2012). The purpose of a literature review is to objectively report on the current knowledge on a topic, based on a summary of previously published research (Green, Johnson \& Adams, 2006). It is a rigorous and highly valued approach to evaluating literature on specific topics. The literature review is also an essential step in the research process and is included in all empirical and review articles $(\mathrm{Wu}$, Aylward, Roberts \& Evans, 2012). A literature review presents a broad perspective on a topic and also describes its history. In addition, it traces development in a specific area (Green et al., 2006) and enables researchers to position their own investigations. Through the identification of relevant concepts and issues, as well as methods of enquiry, researchers can use diverse frameworks for the analysis of their own work (V. Anderson, 2009).

The objective for conducting a literature review is to enable a researcher to write a synthesis of the available literature, 
to discover similarities between different research outputs, to examine differences in the results of the researchers and to identify emerging issues, themes and topics (Kable et al., 2012). De Vos, Strydom, Fouché and Delport (2013) provide a structure for presenting a literature review. They tapped into the seminal work of Babbie and Mouton (2012) and Kerlinger and Lee (2000). De Vos et al. present the building blocks of science under three headings, namely concepts, statements and conceptual frameworks.

\section{Concepts}

Concepts are the most basic building blocks of a body of knowledge. Concepts may be defined as symbolic constructs (Mouton, 1996) by means of which people classify or categorise reality. Terms, words or notions must be available for those aspects of the world that constitute the subject matter of a given scientific discipline. The specific things of which a science tries to make sense are its concepts (De Vos et al., 2013). They are also the most basic building blocks of communication in science. According to Babbie and Mouton (2012), the process of reaching an agreement during a scientific conversation is called conceptualisation and the result or agreement reached is called a concept. Concepts are the primary analytical instruments by means of which one comes to grips with reality. By doing a literature review, a researcher works with the sources from which concepts can be discovered or key concepts generated (Terre Blanche, Durrheim \& Painter, 2009). Concepts then lead to statements and statements to theory building.

\section{Statements}

Once concepts have been formalised, they can be combined into statements, which constitute the next level of the building blocks of knowledge. Statements include definitions, hypotheses and propositions (De Vos et al., 2013), as well as statements of truth (Babbie \& Mouton, 2012).

Definitions are words or constructs that describe other words or constructs (De Vos et al., 2013). According to Mouton (1996), definitions are neither true nor false. Some are just more useful than others. They are used to facilitate communication and argumentation in the sense that they make it possible to say something more easily and clearly than would otherwise be possible (De Vos et al., 2013). The function of a definition is to demarcate the meaning of a word in terms of its sense and reference (Mouton, 1996). The best definitions are those that lead to clear conceptualisations and valid measurements of the phenomena under investigation (Winter, 2000).

A hypothesis is an educated guess (Terre Blanche et al., 2009) or a tentative explanation for an observation, a phenomenon or a scientific problem that can be tested by further investigation, made on the basis of limited evidence (Babbie \& Mouton, 2012). According to De Vos et al. (2013), a hypothesis contains two or more variables that are measurable, or potentially measureable, and that specify how the variables are related. Hypotheses are normally formulated to solve problems in quantitative research.
A proposition is a statement or a sentence that contains demonstrable and testable claims (Mouton, 1996), a judgement or an opinion about the world. Propositions must be tested against reality before they can be accepted as a valid theory or as part of a valid theory (De Vos et al., 2013). Propositions normally form part of a qualitative research project.

Truth statements make epistemic or knowledge claims. Epistemic is derived from the Greek word for truthful knowledge (Babbie \& Mouton, 2012). Statements are accepted as the truth by the scientific community when they are good approximations of reality and when they provide accurate and reliable representations of phenomena (Babbie \& Mouton, 2012). Truth statements may follow after testing hypotheses or investigating propositions.

\section{Conceptual frameworks}

Conceptual frameworks are the integration of scientific statements into a scientific structure (De Vos et al., 2013), which is the next level of the building blocks of scientific knowledge. Hierarchically conceptual frameworks are classified as typologies, models, theories and paradigms. A typology typically fulfils a classifying or categorising function and a model exposes the relationships between concepts, whereas a theory explicates the driving force that explains the relationship between concepts (De Vos et al., 2013). A paradigm provides the broader field in which the conceptual framework functions.

A typology is defined by Mouton (1996) as a conceptual framework in which phenomena are classified in terms of characteristics that they have in common with other phenomena. The different types that comprise the typology should, as far as possible, be mutually exclusive (De Vos et al., 2013). The construction of a typology, according to Mouton, sometimes constitutes the first step in a process that will ultimately culminate in the systematic collection of data. It thus serves as a frame of reference for observation and data collection. It often also provides the most appropriate device for understanding the data (Babbie \& Mouton, 2012).

According to Mouton (1996), a model is like a scientific metaphor. It consists of words that form a description of a social phenomenon, which abstracts the main features of the phenomenon, without an attempt to explain or predict anything (De Vos et al., 2013). Through a study of a specific phenomenon, the researcher reveals certain similarities or relationships and systemises these as a model of that phenomenon (Mouton, 1996). The model is then a framework in which the phenomenon functions. The purpose of models is not to include all features of the system being modelled but only those necessary for research purposes (De Vos et al., 2013).

A theory is an instrument that is aimed at explaining phenomena and events (De Vos et al., 2013). It is based on observable facts and can be proved wrong at any 
time (Higgs \& Smith, 2006). A theory explains by way of casual models or stories, or by postulating a set of casual mechanisms that account for phenomena (Mouton, 1996). Theories vary in scope from very specific explanations (descriptive theories) to fairly large-scale general theories (grand theories) (Dryer, 2006).

The concepts, statements and conceptual framework operate within a larger framework which is called a paradigm. A paradigm in the social sciences can be described as a way of viewing one's own research material and placing it within a broader framework (De Vos et al., 2013). A paradigm can also be described as a system of understanding (Terre Blanche et al., 2009) or a pattern containing a set of legitimate assumptions and a design for collecting and interpreting data (De Vos et al., 2013).

In the literature review, the structure provided by De Vos et al. (2013) is employed because it provides convenient scaffolding for organising knowledge about a specific topic, in this case about business coaching.

\section{The potential value-add of the study}

This study aims to explore and systemise the existing theory in the body of knowledge within business coaching according to the building block for science as described by Mouton (1996). In order to do that, a comprehensive literature review will be conducted.

The value added by this study will be to assist future researchers to have access to the most recent synthesised concepts, definitions, typologies, models, theories and paradigms functioning in the field of business coaching as an academic discipline.

\section{Research design \\ Research approach}

The researchers conducted a systematic review of the literature. By doing this the researchers gained access to the key scientific contributions relevant to the subject (Tranfield, Denyer \& Smart, 2003). The researchers used extensive literature searches of published studies. By using transparent and reproducible procedures, systematic reviews improve the quality and outcome of review processes.

Review processes generally consist of data collection, analysis and synthesis. This study followed the pattern in order to explore the available data to compile the literature review that will be presented below.

\section{Research method}

The research methodology is directly linked to the aim of this article, namely to provide a systematic and qualitative review of published academic literature on business coaching. Systematic reviews are designed to reduce bias (White \& Schmidt, 2005). The methodology specifically developed for systematic literature reviews aims to minimise the effect of the selection of sources, assessment of publications and type of data collected (Nightingale, 2009). The review is qualitative because it does not combine the results of the reviewed studies statistically. It includes a summary and critique of the findings from systematic methods through the processes by which the individual studies are integrated (Green et al., 2006).

\section{Sampling}

Sampling is the selection of research material from an entire body of data (Babbie \& Mouton, 2012). The selected sample must be representative in order for a researcher to draw valid and accurate conclusions (Terre Blanche et al., 2009). Researchers must ensure that the sample is large enough to allow them to make inferences about the entire body of available data. In this case, all the articles that could be found through the specified search engines of the University of South Africa (UNISA) library have been selected. No sampling was done and the whole population was considered.

\section{Data collection methods}

The structure described by Kable et al. (2012) is used as an outline for this literature review. Some reviews of articles have already been published (see Joo, 2005; Kampa-Kokesch \& Anderson, 2001; Kilburg, 1996; Passmore \& Gibbes, 2007); these are acknowledged in the background section of this article. The most recent comprehensive literature review on executive coaching appeared in 2007 and was conducted by Passmore and Gibbes. The main aim of the search was to find articles that presented literature reviews on business coaching. Broad bouquets of Ebsco Host and Emerald Insight, databases consisting of 54 individual search engines, including Business Source Complete and Eric, were used as they have a very broad reach. This was complemented by a Google and Google Scholar search to identify other articles, relevant documents and published reports from conferences or seminar programmes. Nightingale (2009) suggests that this addition was necessary to improve the sensitivity of the search. The search was limited to an electronic search of English language articles published during the past 20 years. Attention was given to the inclusion and exclusion criteria for the search. Inclusion and exclusion criteria should ideally be established in the protocol development stage and should inform the development of a checklist for deciding which studies to include and which to exclude (White \& Schmidt, 2005). Only information or data that are accepted by the scientific community should be included in building the body of knowledge (Babbie \& Mouton, 2012) and as such only published peer-reviewed articles were considered. Articles of which the full text was not available were excluded, as were articles written in an informal style and promotional articles. When the search captured articles in non-academic publications such as magazines, they were also excluded.

Three key terms were used to search the databases, with a focus on the titles of documents. The searched terms 
were coaching, business coaching and executive coaching. The search was conducted in late May 2014. Each of the articles retrieved was assessed for relevance by reading the abstract and, where necessary, the entire paper. The inclusion and exclusion criteria were used to exclude papers that are not relevant to this review. Articles that met the criteria were selected and documented and duplicates were excluded. The results of the search were reported as the number of articles that met the inclusion criteria, as well as the number of cases remaining after the introduction of the exclusion criteria. The quality of the articles was not appraised again. All articles in peer-reviewed journals were included, based on the fact that they had been peer reviewed. Once included in a journal, the articles were deemed sufficient. The articles found during the search are presented chronologically in Appendix 1.

The 12 steps outlined by Kable et al. (2012) were followed in collecting the data. Once the articles had been selected and recorded, they were scrutinised for information relevant to the body of knowledge, as advocated by De Vos et al. (2013).

\section{Data analysis}

The analytical tools function as the lens through which to interrogate the available literature. These tools can be developed before or during engagement with the literature (Terre Blanche et al., 2009). In this study the tools were developed beforehand and are presented below:

- Concepts: Concepts were identified as the words that appeared in the keyword list of the selected articles. When articles did not have a keyword list, no concepts were identified.

- Statements: Only statements that included the word 'definition' or phrases such as 'the phenomenon is described as ...' were included as definitions of the concept. No effort was made to integrate information to construct definitions, as this would introduce bias. The analysis of the articles revealed that no other statements, such as hypotheses, propositions or truth statements were found in more than two articles. The information presented was thus insufficient to warrant in-depth analysis and, as such, definitions were the only focus of further investigation.

- Typologies: Typologies in the text were recognised when they were presented as lists or strings of characteristics associated with the phenomena. The test that was used to identify a typology was to ask if a particular list or string represented the characteristics of the phenomena or if it described types of the phenomena. This is equivalent to the manner in which Babbie and Mouton (2012) describe typologies. If the list or string of statements did not meet these criteria, it was not classified as a typology.

- Models: Models were identified as pieces of text that express the relationship between variables. The focus in models was expressed as relationships, with no reference to the forces driving such a relationship.

- Theories: Theories were identified as pieces of text that explain the relationship between variables, but in which, in addition to models, reference is made to the reasons behind relationships.

- Paradigms: These refer to the broader framework in which the research was positioned. Paradigms were deduced from the general tone of the articles.

\section{Strategies employed to ensure quality data}

According to Babbie and Mouton (2012), reliability refers to the likelihood that a given measurement procedure will deliver the same description of a phenomenon if the measurement is repeated. Validity refers to the extent to which a specific measurement provides data that relates to commonly accepted meanings of a particular concept. In the case of this research project, repeatability was assured by stipulating exactly how the data was collected (see Kable et al., 2012). The validity and trustworthiness was established by means of appropriate sampling of the articles in the field and reading the articles using an appropriate framework (see De Vos et al., 2013).

\section{Reporting}

In reporting the findings a qualitative reporting style will be followed. The findings will be presented in an essay style under different headings and in paragraphs. An appendix with a list of the articles investigated is attached. The articles are numbered. In the result section the findings will be recorded by referring to the article number.

\section{Findings}

The search delivered 84 articles, of which 42 were peer reviewed. Of the 42 , six were promotional articles, leaving the researcher with 36 articles that were suitable for investigation (see Appendix 1).

\section{Finding pertaining to concepts}

In the systematic review, the specified analytical tool found only two concepts associated with coaching and executive coaching, namely management development and leadership development. Fifteen of the 36 articles included a list of keywords. The most common keywords were coaching $(N=12$; see articles $7,10,15,18,19,22,23,26,31,33,40$ and 41$)$ and leadership development $(N=6$; see articles $7,13,18,20,31$ and 35). The third most popular keyword was executive coaching $(N=5$; see articles 13, 15, 24, 35 and 41), followed by management development ( $N=4$; see articles 13, 18, 35 and 41). The other keywords were not mentioned more than three times.

Other keywords included in the different articles were business improvement, business benefits, facilitation, organisational change, organisational development, executive management, executive training, evaluation, planning, business benefits, leadership, team learning, workplace learning, performance and characteristics of coaching, coaching psychology, coaching relationship, business coaching and mentoring. 


\section{Findings pertaining to definitions}

The following 14 statements met the criteria to be included as definitions:

- Article 1: Executive coaching is defined as a helpful relationship. This relationship is formed between a client and a consultant. The client has managerial authority and responsibility in an organisation. The consultant uses a wide variety of behavioural techniques and methods to help the client achieve a mutually identified set of goals. The aim is for the client to improve their professional performance and personal satisfaction and, consequently, to improve the effectiveness of the client's organisation within a formally defined coaching agreement.

- Article 9: Coaching is defined as a form of consultation. It is a formal, ongoing relationship between an individual or team and a consultant. The consultant in this relationship has in-depth knowledge of various psychological paradigms and perspectives regarding behavioural change and organisational functioning. The consultant then provides learning opportunities for the development of self-esteem and self-awareness, as well as increased quality communication with colleagues, peers and subordinates. The consultation techniques give direct behaviourally based feedback and interpretations about the employee's impact on others. The business or organisation will benefit because the behavioural change in the individual or team will lead to enhanced performance.

- Article 13: Coaching is defined as a process of a oneon-one relationship between a professional coach and a coachee for the purpose of enhancing the coachee's behavioural change through self-awareness and learning, and which ultimately contributes to the success of the individual and of the organisation.

- Article 16: Coaching is defined as a natural conversation that follows a predictable process and leads to superior performance, commitment to sustained improvement and positive relationships.

- Article 18: Coaching is an approach to leadership development.

- Article 22: Coaching is the focus of building performance and enhancing well-being in non-clinical populations.

- Article 26: Coaching is defined as the coach's participation in the development and learning process of the person in focus. It is a form of conversation.

- Article 29: Coaching is defined as partnering with clients in a thought-provoking and creative process that inspires them to maximise their personal and professional potential.

- Article 31: Coaching has been defined as a teaching technique for imparting facts and methods for accomplishing a task.

- Article 33: Electronic coaching can be defined as coaching delivered via an electronic medium such as an intranet.

- Article 35: Executive coaching is defined as the teaching of skills in the context of a personal relationship with a learner and the provision of feedback on the executive's interpersonal relations and skills.
- Article 39: Executive coaching is defined as formal, collaborative relationships between clients and consultants to improve their work performance and personal satisfaction, and thereby to improve organisational effectiveness.

- Article41:Coaching is defined as a one-on-one relationship between a professional coach and an executive (coachee).

- Article 42: Coaching is the practice of support to leaders who drive organisational goals.

Although these definitions address a wide range of interpretations of what coaching entails, some communality is evident. These will be presented in the discussion part of this article.

\section{Findings pertaining to typologies}

None of the articles provided a typology of coaching that met the criteria set out in the analytical tools section of this article.

\section{Findings pertaining to models}

From the six articles reporting on models of coaching, six different and distinct models of coaching were identified.

A very early model was found in article 1 . It suggests that an effective coaching model would feature the following steps:

- Developing an intervention agreement.

- Building a coaching relationship.

- Creating and managing expectations of coaching success.

- Providing an experience of behavioural mastery or cognitive control over the problems and issues.

- Evaluating and attributing coaching success or failure.

Article 14 suggests that coaching benefits optimally from a pyramid model as a workable model for coaching. This model has four key factors as its foundation, namely the skills of the coach, the personal attributes of the coach, the coaching process and the coaching environment. The next stage of the model suggests that, when the foundation is in place, the coachee is empowered to realise the level of inner personal benefits, namely clarity and focus, confidence and motivation. After this the coachee is mentally ready to produce the outer personal benefits, namely enhanced skills, knowledge and understanding, and improved behaviour. The coachee will then be equipped and empowered to achieve the pinnacle of the pyramid, namely business results.

In 2006 the four-category model appeared (see article 15). This model defines the approach in terms of the goals of the coaching assignment, the scope of work and the type of business scenarios involved. Each of the four approaches in this model brings with it recommended methods and interventions, qualifications and styles of providers and specific objectives regarding the diverse needs of executives and leadership teams.

Article 25 places considerable emphasis on goal-setting and attainment as introduced by the Goal Attainment Scaling 
(GAS) model as a tool to be used in coaching research and practice. The model presented in article 18 is called the competency-based coaching model. It has the same elements as the model in article 40 . The only difference is that article 18's model adds training, job knowledge and strengths and weakness analysis as extra steps. The model in article 40 suggests that the coaching model contains the following:

- Goal orientation: individual and team-based.

- A strong emphasis on self-reflection and goal-setting.

- The building capacity to work relationally, socially and organisationally. It also focuses on situation or context and the 'here and now'.

- Time limits: contracted relationship for a fixed time.

- Issues of power and influence that are addressed and negotiated as part of the relational process.

From the aforementioned it seems as if the model provided by Leedham (2005) in article 14 is the most prominent because it includes most of the concepts introduced by the other models.

\section{Findings pertaining to theories}

In sum, 14 articles referred directly to theories.

According to article 35, coaching operates within the broader theory of psychotherapy because the concept of 'working alliance' has its roots in psychotherapy. Because of the clienttherapist relationship and the therapeutic intervention, article 1 also places coaching within the broader theory of psychotherapy. Article 2 and article 27 argue that the outcome of coaching must be sustained behavioural change and because that is the focus of an experienced psychologist, the theory in which coaching operates must be that of psychotherapy.

Article 31 places coaching within the leader-member exchange theory (LMX). LMX posits that leaders develop different types of exchange relationships with their subordinates and that the quality of these relationships influences leaders' and subordinates' attitude and behaviours. The social exchange theories maintain that there is a perceived obligation on the part of subordinates to reciprocate high-quality relationships and that these relationships are developed over time through a series of exchanges.

Article 8 and article 41 argue that coaching falls within the parameters of cognitive-behavioural psychology theory and approach because it deals with coping-skills therapies. Article 19 and article 29 link up with coping skills and connect coaching with emotional intelligence, problemsolving therapies and cognitive-restructuring therapies and theories, whilst article 15 positions it within the clinical psychological theory. Article 22 and article 23 use positive psychology and coaching psychology as theories because they focus on building performance and enhancing wellbeing in non-clinical populations.
Article 18 and article 20 identify the theory in which coaching operates as the developmental counselling theory within the broader framework of executive or supervisory development in human resource development. Article 26 links up with the developmental theory and posits coaching within the aesthetic learning theory because it is a cognitive process. Article 21 also supports the cognitive theory, but adds goal-setting theory and action theory. Article 33 goes one step further and claims that this learning process can take place via a virtual process through the Internet as e-coaching.

It appears that the psychotherapy theory $(N=4$; see articles $1,2,27$ and 35) and the developmental theory $(N=3$; see articles 18, 20 and 26) are the theories most often referred to in the field of coaching.

\section{Findings pertaining to paradigms}

The available literature is mainly divided between two paradigms in which coaching functions. Nine articles (Articles 4, 7, 13, 14, 17, 26, 27, 36 and 37) position coaching in the paradigm of management development and more specifically, within human resource development. Some researchers position it within the psychological paradigm. The following eight articles are examples of this: articles 21, $22,23,25,27,32,34$ and 39.

\section{Discussion Outline of findings}

In total 84 articles were located by the search strategy and 36 were analysed according to the inclusion and exclusion criteria described above. All 36 articles were published in the last 18 years. Fourteen articles were published in the last 6 years. These articles were published in a diverse range of accredited academic journals all over the world. Most articles were published in the International Coaching Psychology Review, followed by Journal for Industrial and Commercial Training and Consulting Psychology Journal. No other journal has more than two hits. The result of this search emphasises the notion that only a limited body of research on coaching is available.

With regard to concepts, it must be noted that practitioners of coaching as a profession and academic researchers are still experimenting on arranging concepts into sentences to form statements that can become theories to investigate. Based on their review of current literature and practice, Bond and Seneque (2013) hope that coaching will be conceptualised as a useful tool for managers. Managers must assess what approach might be most suitable to their organisation and personal needs to facilitate sustained change. Coaching struggles conceptually to find its place somewhere between therapy, training, development, mentoring, counselling and interventions (Cilliers, 2005). The approaches to coaching vary in a range from executive coaching (Kilburg, 1996), corporate coaching, business coaching and personal coaching to life coaching, with many variations and permutations in 
between, such as speciality, niche and group coaching (Bond \& Seneque, 2013). Averweg (2010) has added concepts such as virtual coaching and e-coaching to the debate.

Early definitions of coaching found in literature between 1987 and 1992 place a key emphasis on the contribution that coaching can make to improve individual and organisational performance by equipping people with tools, knowledge and opportunities. Definitions constructed between 2001 and 2006 tend to define coaching more as a process and draw a stronger link between coaching, learning, development (articles 3 and 28) and assisting teams and individuals to reach their full potential. Coaching has more recently been defined by some researchers as a personal or organisational intervention (article 2) that builds upon strengths (article 7) and strengthens underdeveloped skills (article 25), and as a systematic activity that seeks to foreground complexity, pluralist perspectives, unpredictability and contextual factors. Article 34 describes coaching as the search for achieving a balance between stability as one of the major contributions that it can make to management interventions.

When one looks at the repetition of keywords in definitions, the following findings have come to light: the words that are repeated in the definitions are 'relationship' $(N=7$; articles $1,9,13,16,35,39$ and 41), 'effectiveness' $(N=7$; articles 1, 9 , 13, 16, 22, 29 and 39), 'learning' ( $N=5$; articles 9, 13, 26, 31 and 35), 'behavioural change' ( $N=3$; articles 1,9 and 13) and 'goal-setting' ( $N=2$; articles 1 and 42).

A comprehensive definition of business coaching, given the aforementioned would thus contain at least these words and could be formulated as follows: Business coaching is a oneon-one relationship with the purpose to change behaviour through learning to improve organisational effectiveness by setting goals to achieve the desired results.

Authors on coaching are silent about typologies. Only one (article 40) of the 36 articles identifies five 'meta' categories. These are management approaches or typologies used in the context of transformational change. The five meta types of management approaches that the article identifies are managing, consulting, mentoring, facilitating and coaching. As a phenomenon, coaching as a type is placed next to these other types of management approaches that are used for transformational change in organisations.

No single model on coaching seems to be dominant. Different models $(N=6$; see articles $1,14,15,18,25$ and 40) were introduced to be followed during the coaching process. The common denominators in these models are goal-setting, self-reflection, behavioural change, situational analysis, timeframe and relational processes.

In 17 of the 36 articles on coaching, theories are presented in which the researchers place the coaching practice or process. Twelve of these articles place the theories within psychological theories and five are positioned within human resources developmental theories. The two human resource developmental theories that were identified are the executive developmental theory and the learning theory. In the domain of psychology, the theories varied from clinical and positive to cognitive-behavioural discourse and psychotherapy.

Two paradigms were identified in which coaching functions, namely human resource development $(N=9$; articles 4,7 , $13,14,17,26,27,36$ and 37) and the psychology paradigm $(N=8$; articles 21, 22, 23, 25, 27, 32, 34 and 39). Article 9 makes the assumption that coaching is customarily studied from behaviourist and humanist paradigms in psychology. Article 14 explicitly states that coaching operates within the positivistic and phenomenological paradigm but does not give any reasons for the statement.

\section{Practical implications}

The building blocks for business coaching as a relatively new and emerging science within the field of business leadership have been defined. This will contribute to the articulation of concepts within this discipline by future researchers and practitioners.

\section{Limitation and recommendations}

Because business coaching is still a newcomer to the world of business, the academic research on the topic is also still in its infancy. Business coaching as such is not an established concept yet. Concepts such as coaching, business coaching, executive coaching, management coaching and even life coaching are used as synonyms. This made it difficult in searching for data on the specific topic of business coaching and can thus be considered a limitation for this study.

It is recommended that research must be stimulated to continue in this field to add data to the body of knowledge.

\section{Conclusion}

This article attempts to contribute to the research on business coaching in more than one way. The literature review proves that the concerns of Cilliers (2005) are valid because the available research is very limited. It also shows that there is a dearth of active researchers and academics currently working in this field. Although the academic data is limited, a number of concepts, models, theories, typologies and paradigms could be identified and may contribute to the systemisation of the body of knowledge.

This article summarises the available data in a way that no previous literature review has done before by using the structure discussed in the methodology section. The model of Kable et al. (2012) has proved to be a systematic method through which the literature review could be structured to eliminate bias and to access a proper sample, and the structure provided by De Vos et al. (2011) has been shown to be useful to organise, integrate and synthesise the data collected. 
- The key concepts associated with coaching are leadership development and executive coaching.

- An inclusive definition of executive coaching reads as follows: Business coaching is a one-on-one relationship with the purpose to change behaviour through learning to improve organisational effectiveness by setting goals to achieve the desired results.

- The most prevalent model of executive coaching is that of Leedham (2005) and it includes the following elements: the skills of the coach, analysis of the situation, improved behaviour and the achievement of business results.

- The most prevalent theory on executive coaching is one that suggests a relationship between psychotherapy and human resource development.

- Two paradigms dominate executive coaching, namely the psychological and human resource developmental paradigms.

Although business coaching is constantly described as a newcomer to the world of business and an academic discipline that is not yet independent, this literature review has proved that in the gap since the last comprehensive literature review has been published, a constant flow of new peer-reviewed articles have been published. This is a tendency that must be encouraged.

\section{Acknowledgements Competing interests}

The authors declare that they have no financial or personal relationships which may have inappropriately influenced them in writing this article.

\section{Authors' contributions}

F.S. (University of South Africa) was responsible for the collection and integration of the data whilst R.S. (University of South Africa) made conceptual contributions to the design and presentation of the research.

\section{References}

Anderson, B. (2007, August 02). Executive coaching: soft of hard core? Finweek, p. 56 Anderson, V. (2009). Research in human resource management. (2nd edn.). London, UK: Charted Institute of Personnel and Development.

April, K.A., \& April, A.R. (2007). Growing leaders in emergent markets: Leadership enhancement in the new South Africa. Journal of Management Education, 31(2) 214-244. http://dx.doi.org/10.1177/1052562906297595

Averweg, U.R. (2010). Enabling role of an intranet to augment e-coaching. Industrial and Commercial Training, 42(1), 47-52. http://dx.doi.org/10.1108/ 00197851011013715

Babbie, E., \& Mouton, J. (2012). The practice of social research. Cape Town, South Africa: Oxford University Press.
Beets, K., \& Goodman, S. (2012). Evaluating a training programme for executive coaches. Journal of Human Resource Management, 10(3), 12-22.

Bond, C., \& Seneque, M. (2013). Conceptualizing coaching as an approach to management and organizational development. Journal of Management Development, 32(1), 57-72. http://dx.doi.org/10.1108/02621711311287026

Bowles, S., Cunningham, C.J.L., De La Rosa, G.M., \& Picano, J. (2007). Coaching leaders in middle and executive management: Goals, performance, buy-in Leadership and Organization Development Journal, 28(5), 388-408. http://dx.doi. org/10.1108/01437730710761715

Cilliers, F.V.N. (2005). Executive coaching experiences: A systems psychodynamic perspective. SA Journal of Industrial Psychology, 31(3), 23-30. http://dx.doi. org/10.4102/sajip.v31i3.205

Clegg, S.R., Rhodes, C., Kornberger, M., \& Stilin, R. (2005). Business coaching: Challenges for an emerging industry. Industrial and Commercial Training, 37(5), 218-223. http://dx.doi.org/10.1108/00197850510609630

De Vos, A.S., Strydom, H., Fouché, C.B., \& Delport, C.S.L. (2013). Research at grass roots: For the social sciences and human services professions. (4th edn.). Pretoria, South Africa: Van Schaik.

Dryer, M.S. (2006). Descriptive theories, explanatory theories, and basic linguistic theory. Trends in linguistics studies and monographs, 167(1), 207-216.

Green, B.N., Johnson, C.D., \& Adams, A. (2006). Writing narrative literature reviews for peer-reviewed journals: Secrets of the trade. Journal of Chiropractic Medicine, 5(3), 102-117. http://dx.doi.org/10.1016/S0899-3467(07)60142-6

Higgs, P., \& Smith, J. (2006). Rethinking truth. (2nd edn.). Cape Town, South Africa: Juta \& Co.

Joo, B. (2005). Executive coaching: A conceptual framework from an integrative review of practice and research. Human Resource Development Review, 4(4), 462-488. http://dx.doi.org/10.1177/1534484305280866

Kable, A.K., Pich, J., \& Maslin-Prothero, S.E. (2012). A structured approach to documenting a search strategy for publication: A 12 step guideline for authors. Nurse Education Today, 32, 878-886. http://dx.doi.org/10.1016/j. nedt.2012.02.022

Kampa-Kokesch, S., \& Anderson, M.Z. (2001). Executive coaching: A comprehensive review of the literature. Consulting Psychology Journal: Practice and Research, 53(4), 205-228. http://dx.doi.org/10.1037/1061-4087.53.4.205

Kerlinger, F.N., \& Lee, H.B. (2000). Foundations of behavioural research. (4th edn.) Fort Worth, TX: Harcourt College Publishers.

Kilburg, R.R. (1996). Toward a conceptual understanding and definition of executive coaching. Consulting Psychology Journal: Practice and Research, 48(2), 134-144. http://dx.doi.org/10.1037/1061-4087.48.2.134

King, P., \& Eaton, J. (1999). Coaching for results. Industrial and Commercial Training 31(4), 145-151. http://dx.doi.org/10.1108/00197859910275791

Leedham, M. (2005). The coaching scorecard: A holistic approach to evaluating the benefits of business coaching. International Journal of Evidence Based Coaching and Mentoring, 3(2), 30-45.

Mouton, J. (1996). Understanding social research. Pretoria, South Africa: Van Schaik.

Nightingale, A. (2009). A guide to systematic literature reviews. Surgery, 27(9), 381-384.

Passmore, J., \& Gibbes, C. (2007). The state of executive coaching research: What does the current literature tell us and what's next for coaching research? International Coaching Psychology Review, 2(2), 116-128.

Shelley, M. (2008). Coaching in construction. Magazine of the South African Institution of Civil Engineering, 16(10), 52-53.

Terre Blanche, M., Durrheim, K., \& Painter, D. (2009). Research in practice. Applied methods for the social sciences. Cape Town, South Africa: University of Cape Town Press.

Tranfield, D., Denyer, D., \& Smart, P. (2003). Towards a methodology for developing evidence-informed management knowledge by means of systematic review. British Journal of Management, 14(3), 207-222. http://dx.doi.org/10.1111/14678551.00375

Upton, P. (2006, August 10). Sport can learn from business. Finweek, pp. 48-49.

White, A., \& Schmidt, K. (2005). Systematic literature reviews. Complementary therapies in medicine, 13, 54-60. http://dx.doi.org/10.1016/j.ctim.2004.12.003

Winter, G. (2000). A comparative discussion of the notion of 'validity' in qualitative and quantitative research. The Qualitative Report, 4(3\&4), 3-6.

Wu, Y.P., Aylward, B.S., Roberts, M.C., \& Evans, S.C. (2012). Searching the scientific literature: Implications for quantitative and qualitative reviews. Clinical Psychology Review, 32, 553-557. http://dx.doi.org/10.1016/j.cpr.2012.06.007 


\section{Appendix 1}

TABLE A1: Chronological list of articles selected for the research.

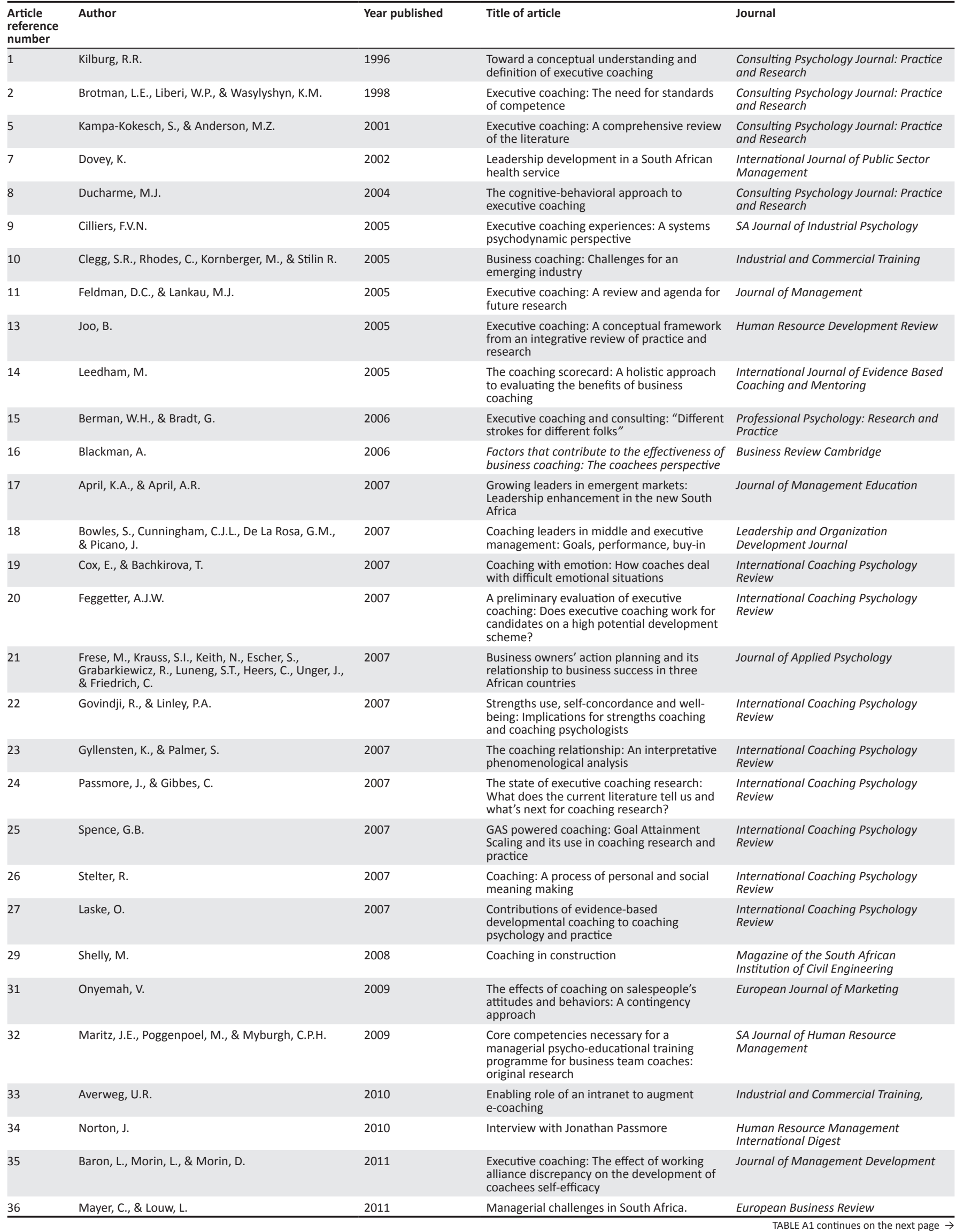


TABLE A1 (Continues...): Chronological list of articles selected for the research.

\begin{tabular}{|c|c|c|c|c|}
\hline $\begin{array}{l}\text { Article } \\
\text { reference } \\
\text { number }\end{array}$ & Author & Year published & Title of article & Journal \\
\hline 37 & Beets, K., \& Goodman, S. & 2012 & $\begin{array}{l}\text { Evaluating a training programme for } \\
\text { executive coaches }\end{array}$ & $\begin{array}{l}\text { Journal of Human Resource } \\
\text { Management }\end{array}$ \\
\hline 38 & Lewis-Duarte, M., \& Bligh, M.C. & 2012 & $\begin{array}{l}\text { Agents of "influence": Exploring the usage, } \\
\text { timing, and outcomes of executive coaching } \\
\text { tactics }\end{array}$ & $\begin{array}{l}\text { Leadership and Organization } \\
\text { Development Journal }\end{array}$ \\
\hline 39 & Motsoaledi, L., \& Cilliers, F. & 2012 & $\begin{array}{l}\text { Executive coaching in diversity from the } \\
\text { systems psychodynamic perspective }\end{array}$ & SA Journal for Industrial Psychology \\
\hline 40 & Bond, C., \& Seneque, M. & 2013 & $\begin{array}{l}\text { Conceptualizing coaching as an approach } \\
\text { to management and organizational } \\
\text { development }\end{array}$ & Journal of Management Development \\
\hline 41 & Bozer, G., Sarros, J.C., \& Santora, J.C. & 2013 & $\begin{array}{l}\text { The role of coachee characteristics in } \\
\text { executive coaching for effective sustainability }\end{array}$ & Journal of Management Development \\
\hline 42 & Maltbia, T.E., Marsick, V.J., \& Ghosh, R. & 2014 & $\begin{array}{l}\text { Executive and organizational coaching: A } \\
\text { review of insights drawn from literature to } \\
\text { inform HRD Practice }\end{array}$ & $\begin{array}{l}\text { Advances in Developing Human } \\
\text { Resources }\end{array}$ \\
\hline
\end{tabular}

